\title{
MOLLI $T_{1}$ mapping versus $T_{2} \mathrm{~W}$-SPAIR at 3T: myocardial area at risk measurements and the influence of microvascular obstruction
}

Donnie Cameron ${ }^{1 *}$, Nishat Siddiqi ${ }^{1}$, Christopher J Neil ${ }^{2,1}$, Baljit Jagpal ${ }^{1}$, Margaret Bruce ${ }^{1}$, Andrew Richardson ${ }^{1}$, Thomas W Redpath", Michael P Frenneaux', Dana K Dawson ${ }^{1}$

From 17th Annual SCMR Scientific Sessions

New Orleans, LA, USA. 16-19 January 2014

\section{Background}

Robust CMR imaging is required for the delineation of myocardial area at risk (AAR), so that the success of reperfusion therapies can be evaluated. In this work, we investigate the performance of $\mathrm{T}_{1}$ mapping in assessing AAR one week post-STEMI, and explore the effect of microvascular obstruction (MVO) on $\mathrm{T}_{1}$ relaxation times.

\section{Methods}

CMR imaging was conducted on a Philips 3T Achieva MRI scanner. $\mathrm{T}_{2} \mathrm{~W}$-weighted spectral attenuated inversion recovery $\left(\mathrm{T}_{2} \mathrm{WW}\right.$-SPAIR), modified look-locker inversion recovery (MOLLI) $\mathrm{T}_{1}$ mapping and late gadolinium enhancement (LGE) sequences were applied as short axis stacks in 10 healthy volunteers and 62 STEMI patients.
Receiver operator characteristic (ROC) analysis was applied to calculate a cut-off $\mathrm{T}_{1}$ to to discriminate AAR from normal myocardium. The presence of LGE was used as the positive ROC test state, while healthy myocardium, as measured in volunteers, was used as the negative ROC test state. For comparison with T1 mapping, the AAR was also measured on $\mathrm{T}_{2} \mathrm{WW}$ images using a threshold signal intensity $>2 \mathrm{SD}$ greater than remote. The derived myocardial edema volumes and salvage indices were compared between $\mathrm{MVO}+$ and MVO- groups.

\section{Results}

For $\mathrm{T}_{1}$ mapping, $\mathrm{ROC}$ analysis gave a significantly larger area-under-the-curve (AUC) as compared to $\mathrm{T}_{2} \mathrm{WW}$ SPAIR for delineating myocardial edema $(\mathrm{AUC}=0.89$

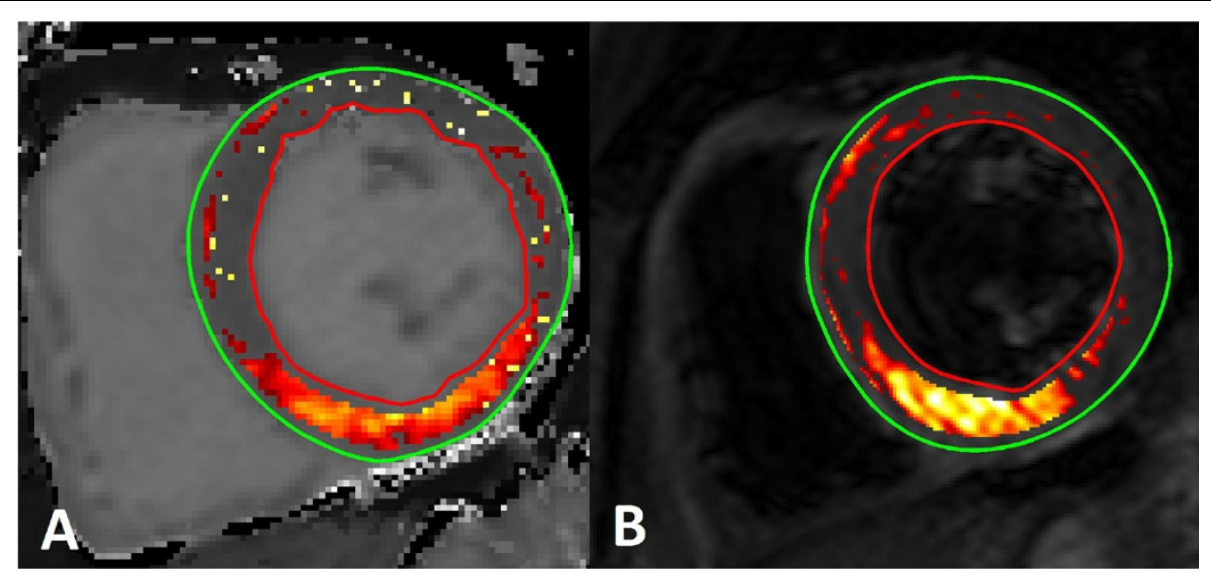

Figure 1 The area at risk as delineated by (A) MOLLI $T_{1}$ mapping and (B) $T_{2}$-weighted SPAIR. 
Table 1 Area at Risk and Salvage Index

\begin{tabular}{cccc}
\hline Method & All Patients & MVO+ & MVO- \\
\hline T $_{2}$ W-SPAIR 2SD AAR Volume (\%) & $40(16)$ & $28(11) \dagger$ & $48(13) \dagger$ \\
$\mathrm{T}_{1}$ Mapping ROC AAR Volume (\%) & $55(7)^{*}$ & $57(7)^{*}$ & $53(8)$ \\
Salvage Index by T W-SPAIR 2SD & $0.66(0.23)$ & $0.75(0.17)$ & $0.59(0.25)$ \\
Salvage Index by T, Mapping ROC & $0.73(0.22)$ & $0.89(0.08)^{*}+$ & $0.63(0.22) \dagger$
\end{tabular}

Area at risk volume and salvage index measured using $T_{2} W$-SPAIR and $T_{1}$ mapping - * denotes a statistically significant difference between $T_{1}$ mapping and $T_{2} W$ SPAIR techniques; + denotes a statistically significant difference between MVO+ and MVO- groups ( $p$ values in the text). Data is presented as mean (SD).

vs $0.83, \mathrm{p}=0.009)$ as well as better sensitivity/specificity $(83 / 83 \%$ vs $73 / 73 \%)$. Neither method was significantly affected by the presence of MVO. The calculated ROC cut-off for $\mathrm{T}_{1}$ mapping was $1243 \mathrm{~ms}$, and this gave a significantly larger AAR than that measured with a $\mathrm{T}_{2} \mathrm{~W}$-SPAIR 2SD threshold $(\mathrm{p}=0.006)$. Using the $\mathrm{T}_{1}$ mapping cut-off, patients with MVO had a significantly larger AAR and a poorer salvage index than patients without MVO ( $\mathrm{p}<0.05$ for both). The AAR measured using each of the two methods is illustrated in Figure 1, and AAR and salvage index measurements are shown in Table 1.

\section{Conclusions}

$\mathrm{T}_{1}$ mapping at $3 \mathrm{~T}$ can be used to automatically delineate AAR one week post-STEMI. It delimits larger volumes of edema and demonstrates less variability than $\mathrm{T}_{2} \mathrm{WW}$-SPAIR. MVO did not significantly affect the discriminatory power of either of these techniques at seven days post-STEMI.

\section{Funding}

This study was supported by a Medical Research Council (UK) grant, as a sub-study of Nitrites in Acute Myocardial Infarction, NCT01388504.

\section{Authors' details}

${ }^{1}$ University of Aberdeen, Aberdeen, UK. ${ }^{2}$ The Queen Elizabeth Hospital,

Adelaide, South Australia, Australia.

Published: 16 January 2014
doi:10.1186/1532-429X-16-S1-O22

Cite this article as: Cameron et al:: MOLLI $\mathrm{T}_{1}$ mapping versus $\mathrm{T}_{2} \mathrm{~W}$ -

SPAIR at 3T: myocardial area at risk measurements and the influence of microvascular obstruction. Journal of Cardiovascular Magnetic Resonance 2014 16(Suppl 1):O22.
Submit your next manuscript to BioMed Central and take full advantage of:

- Convenient online submission

- Thorough peer review

- No space constraints or color figure charges

- Immediate publication on acceptance

- Inclusion in PubMed, CAS, Scopus and Google Scholar

- Research which is freely available for redistribution

Submit your manuscript at www.biomedcentral.com/submit 